\title{
Differential effects of d-amphetamine in mature and immature rats
}

\author{
RICHARD H. BAUER \\ University of California, Los Angeles, California 90024 \\ and \\ DEBRA L. DUNCAN \\ University of Houston, Houston, Texas 77004
}

\begin{abstract}
Twenty-eight- to 33- and 120- to 140-day-old male Sprague-Dawley rats were injected with physiological saline, 2.0 , or $5.0 \mathrm{mg} / \mathrm{kg} \mathrm{d}$-amphetamine. Thirty minutes after the injection, they explored an open field for $8 \mathrm{~min}$ and were then trained in a one-way avoidance task. Mature animals were more active in the inner portion of the open field following $2.0 \mathrm{mg} / \mathrm{kg}$ and acquired the avoidance task more rapidly than those given saline or $5.0 \mathrm{mg} / \mathrm{kg}$. Neither drug dose altered activity or avoidance of immature animals. Both mature and immature rats had shorter escape latencies to footshock following the drug. Differential effects of d-amphetamine in mature and immature animals are probably due to developmental changes in brain norepinephrine and/or dopamine.
\end{abstract}

Very few studies have compared the behavioral effects of drugs in mature and immature animals, in spite of the fact that levels of some central nervous system chemicals altered by drugs differ in mature and immature animals. In one of the few reports comparing different age groups treated with d-amphetamine (d-A), Sofia (1969) found that $1.0 \mathrm{mg} / \mathrm{kg}$ increased activity of 32-day-old rats, but that this increase was less than in mature rats. Although no statistics were reported, Campbell, Lytle, and Fibiger (1969) concluded that doses of $.25-8.0 \mathrm{mg} / \mathrm{kg}$ d-A produced similar activity increases in 10-, 15-, 20-, 25-, and 100-day-old rats.

Increased motor activity following d-A is thought to be due to action of the drug on brain norepinephrine (NE) while increased stereotyped behaviors are associated with alterations in dopamine- (DA) mediated pathways (e.g., Geyer, Segal, \& Mandell, 1972; Taylor \& Snyder, 1971). However, the catecholaminergic systems thought to underlie the behavioral effects of $d$-A undergo age-dependent changes in the rat from birth to maturity. For example, regional studies during development indicate that forebrain $\mathrm{NE}, \mathrm{DA}$, and their related enzymes approach adult levels at approximately 45 days of age (Porcher \& Heller, 1972) and in the hippocampus, amygdala, and hypothalamus NE increases by $200 \%-400 \%$ from 10 to 51 days of age (Weiner \& Ganong, 1972). Whole brain NE, DA, and tyrosine hydroxylase increase approximately $60 \%$ from $10-40$ days of age and remain relatively constant thereafter (e.g., Breese \& Traylor, 1972). Catecholamines are also more sensitive to the depleting action of reserpine and tetrabenazine in 11- and 23-day-old rats than in adults

*This research was supported by Grant MH24384-01 to Joaquin M. Fuster and Richard $H$. Bauer and by personal funds of the authors.
(Kulkarni \& Shideman, 1966). Since reduction of NE in adult rats reduces or eliminates the behavioral effects of d-A (Creese \& Iversen, 1973; Miller, Cox, \& Maickel, 1970), in some situations immature animals would be expected to react differently to d-A than adults because of their lower NE and DA levels.

The present study compared the effects of d-A on open-field activity, reactivity to footshock, and avoidance learning in mature and immature rats. In addition, research concerned with alteration of defensive behavior by $\mathrm{d}-\mathrm{A}$ in the rat is inconsistent (Cappell, Ginsberg, \& Webster, 1972; Kumar, 1968). To clarify further the action of d-A on defensive behavior, activity nearest the walls was considered separately from activity in the remaining inner portion of the open field. Freezing and crouching nearest the walls of an open field are considered to be defensive postures of the rat (e.g., Grossen \& Kelley, 1972).

\section{METHOD}

\section{Subjects}

The subjects were 60 experimentally naive male albino Sprague-Dawley rats obtained from Texas Inbred, Houston, Texas $(\mathrm{N}=10$ /group). All rats were weaned by the breeder at 20-21 days of age. Immature animals arrived at 21 days of age and were tested at 28-33 days of age. Mature animals arrived at approximately 80 days of age and were tested at 120-140 days of age. All animals were housed in pairs in standard laboratory cages. The tail of one animal in each cage was marked with colored ink for identification. Light onset and light offset in the colony room were at 6 a.m. and 6 p.m., respectively. The colony room had a mean temperature of $72^{\circ} \mathrm{F}$. During all phases of the experiment, the rats had ad lib access to food (Purina Lab Chow) and water. All experimental testing was done between 9 a.m. and 4 p.m., and within this interval an equal number of subjects from each group was tested. 


\section{Apparatus}

Activity of mature animals was measured in an 80-cm-square open field with $40-\mathrm{cm}$-high walls. The plywood walls were painted medium gray, and the light tan tile floor was sectioned into $6410 \times 10 \mathrm{~cm}$ squares by $1-\mathrm{mm}$ black lines. The open field was illuminated by a 120 -cm-long fluorescent bulb mounted $2.5 \mathrm{~m}$ above the open field. Immature animals were tested in an identical apparatus, except the dimensions of the open field and squares on the floor were reduced by $25 \%$ to equate for size differences of the two age groups.

The walls of the one-way avoidance apparatus were Plexiglas, and the floor was constructed of $2 \mathrm{~mm}$-in-diam stainless steel bars placed $14 \mathrm{~mm}$ apart (center-to-center). When training mature animals, both the startbox and goalbox were $30 \mathrm{~cm}$ long, $12 \mathrm{~cm}$ wide, and $16 \mathrm{~cm}$ high and were separated by a $4-\mathrm{cm}$-high hurdle and hand-operated door. When training immature subjects, dimensions of the avoidance apparatus were reduced by $25 \%$ by inserting Plexiglas inner liners. Height of the barrier was also reduced by $25 \%$. The startbox walls were covered with medium-gray paper, and the goalbox walls with black paper. Raising and lowering the door between the two compartments activiated and terminated the CS, US, and a timer. The CS was a 75-dB 4.5-Kc tone generated by a Mallory "Sonalert" (Model CS628H) placed $30 \mathrm{~cm}$ above the apparatus. The US was a $2.0-\mathrm{mA}$ footshock generated by a Foringer shock generator and scrambler.

\section{Procedure}

Subjects were removed from their cages by the tails, weighed, and given an intraperitoneal injection of physiological saline, 2.0, or $5.0 \mathrm{mg} / \mathrm{kg} \mathrm{d}-\mathrm{A}$ sulfate in physiological saline. Doses were individually regulated to $.01 \mathrm{cc} / \mathrm{g}$ of body weight, and the bottles containing the solutions were coded so the experimenter did not know the solution being injected. Following the injection, the subjects were returned to their home cages for $30 \mathrm{~min}$ before an 8-min period of exploration in the open field. During open-field testing, each subject was placed in a corner facing outward. The path of the rat as it crossed the squares was traced on a $20-\mathrm{cm}$ square map of the open field. A square was considered crossed when both front paws crossed one of the lines painted on the floor. Number of squares crossed by each animal in the row nearest the walls and those in the remaining inner portion of the open field were later determined from these maps. The floor and walls were cleaned with a damp paper towel after each animal was tested.

Immediately after open-field testing, subjects were trained in the one-way avoidance apparatus to a criterion of 9 out of 10 avoidances or a total of 70 trials. The animals were adapted to the startbox for 30-60 sec, and a trial was begun only when the animal was facing the door. Avoidance training required the rat to cross from the startbox to the goalbox before the 5-sec CS-US interval elapsed. When the animal crossed into the goalbox, the door was lowered and the rat was confined there for $5 \mathrm{sec}$. The 30 -sec intertrial interval was spent in a $40-\mathrm{cm}$-high holding box.

\section{RESULTS}

Mean number of squares crossed per minute in the row nearest the walls are presented in the upper panel of Fig. 1 as a function of age and drug dose. Mean number of squares crossed in the remaining inner portion of the open field are presented in the lower panel of Fig. 1. Comparison of these two figures indicates that d-A had little affect on immature rats, but mature rats given $2.0 \mathrm{mg} / \mathrm{kg}$ are more active in the inner portion of the open field.

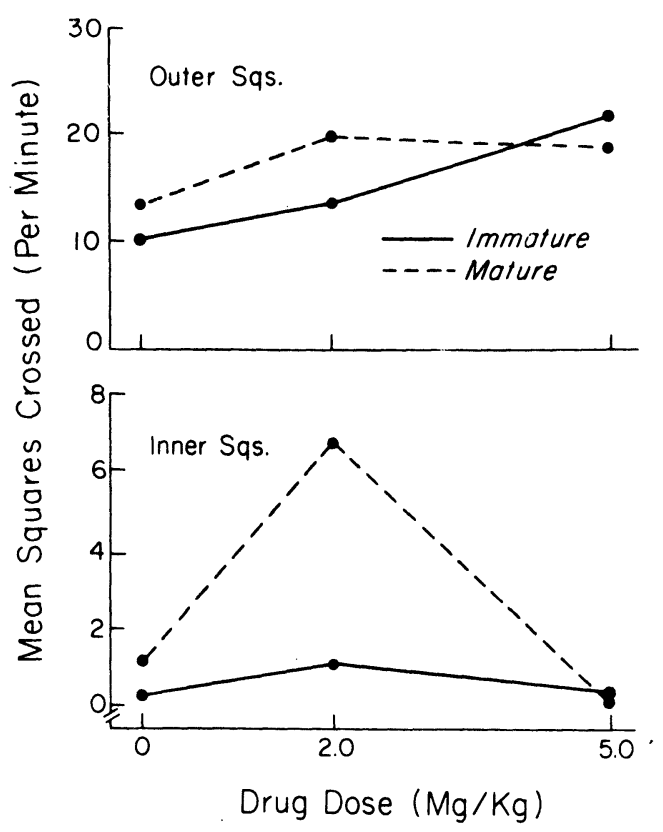

Fig. 1. Mean number of squares crossed per minute in the outer (upper panel) and inner (lower panel) squares of an open field as a function of age and drug dose.

Activity in the outer and inner portions of the open field was analyzed separately by 2 by 3 factorial analysis of variance, supplemented by Tukey a tests in performing post hoc comparisons between individual treatment means. Analysis of the number of squares crossed in the row nearest the walls revealed no significant main effects or interaction. Analysis of the number of squares crossed in the inner squares revealed that older animals crossed significantly more squares than younger $(F=8.17, \mathrm{df}=1 / 54, \mathrm{p}<.01)$ and those receiving $\mathrm{d}$-A crossed more squares than saline controls $(\mathrm{F}=8.85, \mathrm{df}=2 / 54, \mathrm{p}<.01)$. The Age by Drug interaction was also significant $(F=5.33, \mathrm{df}=2 / 54$, $\mathrm{p}<.01$ ). Tukey a test indicated that mature animals injected with $2.0 \mathrm{mg} / \mathrm{kg}$ crossed significantly more inner squares than all other groups $(\mathrm{p}<.01)$. Thus, $2.0 \mathrm{mg} / \mathrm{kg}$ markedly increased activity of mature animals in the inner portion of the open field but neither drug dose altered activity of immature animals.

Figure 2 presents the mean number of trials to criterion during avoidance training. A 2 by 3 analysis of variance of the number of trials to criterion revealed that animals injected with the drug reached criterion in significantly fewer trials $(\mathrm{F}=5.11, \mathrm{df}=2 / 54, \mathrm{p}<.02)$. Tukey a test indicated that mature rats administered $2.0 \mathrm{mg} / \mathrm{kg}$ reached criterion in significantly fewer trials than all other groups $(p<.01)$. There were no significant differences between immature animals treated with saline or the drug.

Figure 3 presents mean escape latencies per trial for 


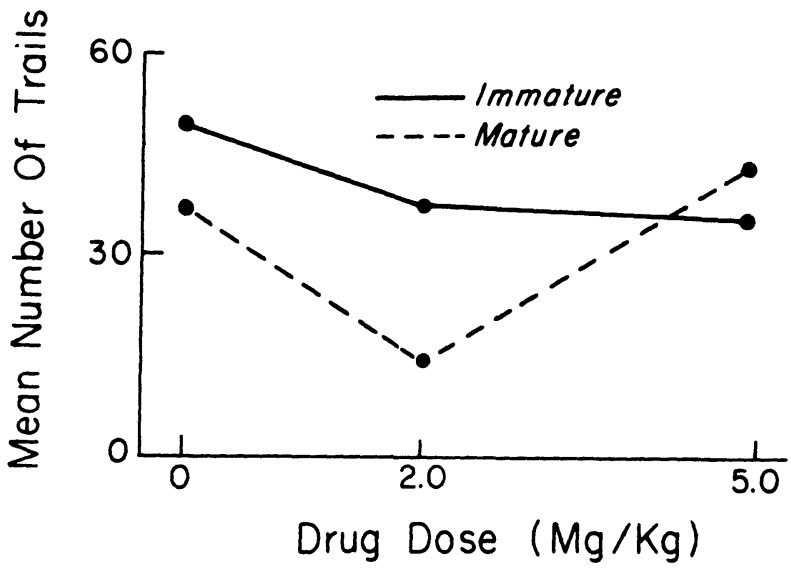

Fig. 2. Mean number of trials required to a criterion of 9 out of $\mathbf{1 0}$ avoidances as a function of age and drug dose.

the first three trials. Only the first three trials were considered, since these latencies would be relatively unaffected by learning. As can be seen, both mature and immature animals treated with d-A have shorter escape latencies than saline controls. Since the variance in the saline-treated groups was significantly larger than in the drug-treated groups, these data were analyzed by nonparametric statistics. Mann-Whitney U tests indicated that immature animals injected with saline had significantly longer latencies than immature animals treated with $2.0 \mathrm{mg} / \mathrm{kg}(\mathrm{p}<.02)$ but did not differ significantly from those given $5.0 \mathrm{mg} / \mathrm{kg}(\mathrm{p}<.10)$. Therefore, in spite of the fact that immature animals injected with $2.0 \mathrm{mg} / \mathrm{kg}$ had shorter escape latencies than their saline controls, both groups acquired the avoidance task in approximately the same number of trials. Mature animals injected with saline had significantly longer escape latencies than mature animals treated with $2.0 \mathrm{mg} / \mathrm{kg} \quad(\mathrm{p}<.05)$ and $5.0 \mathrm{mg} / \mathrm{kg}$ $(p<.02)$. These results indicate that, although mature subjects given 2.0 and $5.0 \mathrm{mg} / \mathrm{kg}$ had significantly shorter escape latencies than their saline controls, only the $2.0-\mathrm{mg} / \mathrm{kg}$ group acquired the avoidance task in fewer trials.

\section{DISCUSSION}

Results of the present experiments indicate that mature rats treated with $2.0 \mathrm{mg} / \mathrm{kg}$ d-A were more active in the inner portion of the open field, acquired a one-way avoidance task more rapidly, and had shorter escape latencies. Unlike mature animals, $2.0 \mathrm{mg} / \mathrm{kg}$ did not alter activity or avoidance of immature rats but decreased escape latencies. A $5.0-\mathrm{mg} / \mathrm{kg}$ dose increased reactivity to footshock but did not alter activity or avoidance of mature rats. Administration of $5.0 \mathrm{mg} / \mathrm{kg}$ to immature resulted in only a marginal decrease in escape latencies.

The finding that an intermediate dose of d-A increased open-field activity while higher doses decreased activity of mature rats is consistent with previous reports (Fog, 1970; Schiorring, 1971). Mature rats treated with $1.0 \mathrm{mg} / \mathrm{kg}$ d-A are also reported to remain longer in the center of an open field than saline controls (Fog, 1970). However, neither drug dose altered activity of immature rats. These results are similar to those of Sofia (1969) but at variance with the conclusion of Campbell et al (1969). A number of procedural differences could be responsible for these findings. Age differences may account for these results, because Weiner and Ganong (1972) observed a significant decline in hypothalamic and hippocampal NE from 30 to 37 days of age, followed by a further increase. Differences in apparatus characteristics may also be an important factor because d-A produces dissimilar effects in different testing situations (e.g., Kumar, 1969). Sofia (1969) recorded activity in a somewhat smaller open field $(42 \times 23 \mathrm{~cm})$ than that used in the present study. Campbell et al (1969) recorded activity of immature rats in $6.3 \times 7.5 \mathrm{~cm}$ tilt cages and mature animals in $17.5 \times 20.0 \mathrm{~cm}$ cages. In addition, their rats were adapted to the cages for $30 \mathrm{~min}$ prior to drug treatment and activity was recorded for a much longer period following the injection. Since animals in the Campbell et al study were adapted to a relatively small chamber and exposed to the apparatus for a much longer period, activity in this situation is generally considered exploratory behavior. Decreased open-field activity and crouching near the walls is thought to be a defensive posture of the rat to a fearful situation. Therefore, in the Campbell et al study, action of the drug on the exploratory behavior may be involved but in a much larger open field, d-A alteration of defensive behavior may be the more important factor. Developmental studies of the rat also support this hypothesis. Exploratory behavior increases rapidly from

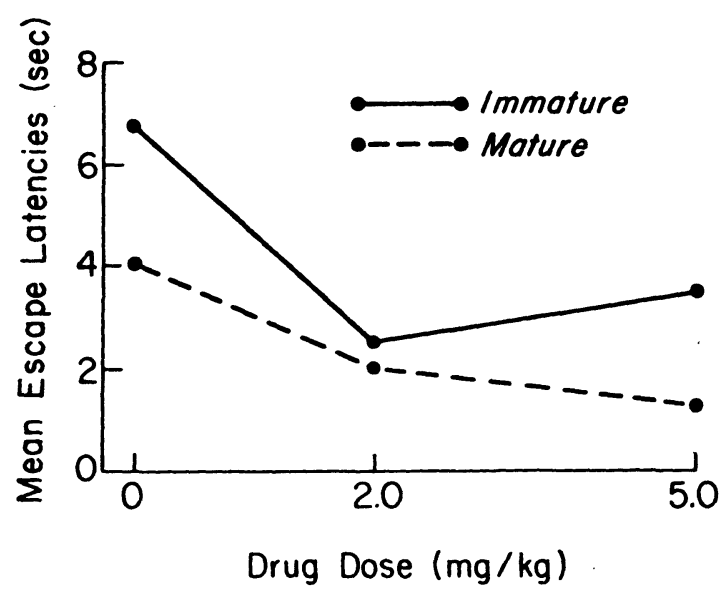

Fig. 3. Mean escape htencies per trial for the first three trials of one-way avoidance training as a function of age and drug dose. 
10 to 20 days of age and then declines sharply (Bolles \& Woods, 1964). Freezing to novel stimuli first occurs at 23 days of age (Bolles \& Woods, 1964) and fear, as measured by open-field activity and defecation, develop from 20 to 45 days of age (Candland \& Campbell, 1962). Thus, d-A may increase the fully developed exploratory behavior of both mature and immature rats but not alter the incompletely developed defensive behavior of immature rats. However, this interpretation must be considered with caution because, in the present experiment, activity of mature and immature saline controls was quite similar.

More rapid avoidance acquisition of mature rats following $2.0 \mathrm{mg} / \mathrm{kg}$ and a return to levels near saline controls with a higher dose is also consistent with previous reports (e.g., Lyon \& Randrup, 1972; Satinder, 1971). The finding that the mature $2.0-\mathrm{mg} / \mathrm{kg}$ group had shorter escape latencies and acquired the avoidance task

More rapid avoidance acquisition of mature rats following $2.0 \mathrm{mg} / \mathrm{kg}$ and a return to levels near saline controls with a higher dose is also consistent with previous reports (e.g., Lyon \& Randrup, 1972; Satinder, 1971). The finding that the mature $2.0-\mathrm{mg} / \mathrm{kg}$ group had shorter escape latencies and acquired the avoidance task more rapidly suggests that faster acquisition was due to increased reactivity to footshock. However, mature subjects treated with $5.0 \mathrm{mg} / \mathrm{kg}$, and immature treated with 2.0 and $5.0 \mathrm{mg} / \mathrm{kg}$, also had shorter escape latencies than the saline controls, but acquisition of these groups was not facilitated. These findings suggest that more rapid acquisition of the mature $2.0-\mathrm{mg} / \mathrm{kg}$ group was not due to increased reactivity to footshock. These results also tend to rule out the possibility that faster acquisition was due to a drug-induced disruption of freezing to the US. However, disruption of freezing cannot be excluded as a factor because d-A is known to reduce freezing to footshock (e.g., Satinder, 1971). Also, in the present study, increased activity of the mature $2.0-\mathrm{mg} / \mathrm{kg}$ group occurred primarily in the inner portion of the open field, which further suggests that d-A disrupts freezing. Faster acquisition could also be due to more rapid learning but results of the present experiment offer no evidence for or against this hypothesis.

Comparison of mature and immature rats indicates that the two age groups are differentially affected by d-A. Activity, avoidance, and escape latencies were altered by 2.0 and/or $5.0 \mathrm{mg} / \mathrm{kg}$ in mature rats but only escape latencies were altered in immature animals. Since the dose-response relationship of $\mathrm{d}-\mathrm{A}$ and most behaviors is a U-shaped function, failure to find increased activity and avoidance in immature rats could be the result of either a lesser or a greater sensitivity to d-A on the part of immature rats. Newborn and immature animals are known to be more sensitive to other drugs than adults, and this effect is thought to be due to decreased permeability of the blood-brain barrier as a function of increasing age (Serini \& Principi, 1968). Thus, failure to find increased activity and avoidance with immature rats could be the result of greater access of d-A to NE and DA storage sites in the immature rat. However, Loizou (1970) reported that the blood-brain barrier to circulating monoamines is developed in 2-week-old rats. These results suggest that the differential d-A effects are not due to greater access of d-A to NE and DA storage sites in the immature rat and tend to rule out the possibility that immature rats are more sensitive to the drug.

Regional studies during development indicate that NE, DA, and their related enzymes in most brain areas of 30-day-old rats are approximately $60 \%$ of adult levels (Porcher \& Heller, 1972). A considerable amount of evidence also indicates that the behavioral effects of $\mathrm{d}-\mathrm{A}$ are the result of increased release and prevention of reuptake of these amines (e.g., Taylor \& Snyder, 1971). Thus, the differential effects of d-A found in the present study may be due to developmental changes in the release or prevention of reuptake of NE and/or DA or to the lower levels of these amines in immature animals.

\section{REFERENCES}

Bolles, R. C., \& Woods, P. J. The ontogeny of behaviour in the albino rat. A nimal Behaviour, 1964, 12, 427-441.

Breese, G. R.. \& Traylor, T. D. Developmental characteristics of brain catecholamines and tyrosine hydroxylase in the rat: Effects of 6-hydroxydopamine. British Journal of Pharmacology, 1972, 44, 210-233.

Campbell, B. A., Lytle, L. D., \& Fibiger, H. C. Ontogeny of adrenergic arousal and cholinergic inhibitory mechanisms in the rat. Science, $1969,166,635-637$.

Candland, D. K., \& Campbell, B. A. Development of fear in the rat as measured by behavior in the open field. Journal of Comparative and Physiological Psychology, 1962, 55, 593-596.

Cappell, H., Ginsberg, R., \& Webster, C. D. Amphetamine and conditioned "anxiety.", British Journal of Pharmacology, $1972,45,525-531$.

Creese, I., \& Iversen, S. D. Blockage of amphetamine induced motor stimulation and stereotype in the adult rat following neonatal treatment with 6-hydroxy do pamine. Brain Research, $1973,55,369-382$.

Fog, R. Behavioural effects in rats of morphine and amphetamine and of a combination of the two drugs. Psychopharmacologia, 1970, 16, 305-312.

Geyer, M. A., Segal, D. S., \& Mandell, A. J. Effect of intraventricular infusion of dopamine and norepinephrine on motor activity. Physiology and Behavior, 1972, 8, 653-658.

Grossen, N. E., \& Kelley, M. J. Species-specific behavior and acquisition of avoidance behavior in rats. Journal of Comparative and Physiological Psychology, 1972, 81, 307-310.

Kulkarni, A. S., \& Shideman, F. E. Sensitivities of the brains of infant and adult rats to the catecholamine depleting actions of reserpine and tetrabenazine. Journal of Pharmacology and Experimental Therapeutics, 1966, 153, 428-433.

Kumar, R. Exploration and latent learning: Differential effects of dexamphetamine on components of exploratory behaviour in rats. Psychopharmacologia, 1969, 16, 54-72.

Kumar, R. Psycho-active drugs, exploratory activity and fear. Nature, 1968, 218, 665-667.

Loizou, L. A. Uptake of monamines into central neurons and the blood-brain barrier in the infant rat. British Journal of Pharmacology, 1970, 40, 800-813.

Lyon, M., \& Randrup, A. The dose-response effect of amphetamine upon avoidance behaviour in the rat seen as a function of increasing stereotypy. Psychopharmacologia, 1972, 23, 334-347.

Miller, F. P., Cox, R. H., \& Maickel, R. P. The eff ects of altered brain norepinephrine levels on continuous avoidance responding and the action of amphetamines. Neuropharmacology, 1970, 9, 511-517. 
Porcher, W., \& Heller, A. Regional development of catecholamine biosynthesis in rat brain. Journal of Neurochemistry, 1972, 19, 1917-1930.

Satinder, K. P. Genotype-dependent effects of d-amphetamine sulfate and caffeine on escapeavoidance behavior of rats. Journal of Comparative and Physiological Psychology, 1971, 76, 359-364.

Schiorring, E. Amphetamine induced selective stimulation of certain behaviour it ems with concurrent inhibition of others in an open-field test with rats. Behaviour, 1971, 39, 1-17.

Sereni, F., \& Principi, N. Developmental pharmacology. Annual R eview of Pharmacology, 1968, 8, 453-466.

Sofia, R. D. Effects of chlorpromazine and d-amphetamine in
Long Evans rats of different age, body weight and brain weight. Archives International Pharmacodynamics, 1969, 182, 139-146.

Taylor, K. M., \& Snyder, S. H. Differential effects of d- and l-amphetamine on behavior and on catecholamine disposition in dopamine and norepinephrine containing neurons of rat brain. Brain Research, 1971, 28, 295-309.

Weiner, R. I., \& Ganong, W. F. Norepinephrine concentration in the hypothalamus, amygdala, hippocampus, and cerebral cortex during postnatal development and vaginal opening. Neuroendocrinology, 1972, 9, 65-71.

(Received for publication January 21, 1974; revision received August 20, 1974.)

\section{ERRATUM}

Andreassi, J. L., DeSimone, J. J., Friend, M. A., \& Grota, P. A. Hemispheric amplitude asymmetries in the auditory evoked notential with monaural and binaural stimulation. Physiological Psychology, 1975, 3 (2), 169-171. A portion of Figure 1, on page 171, was inadvertently omitted. It is reproduced in its entirety below.

A
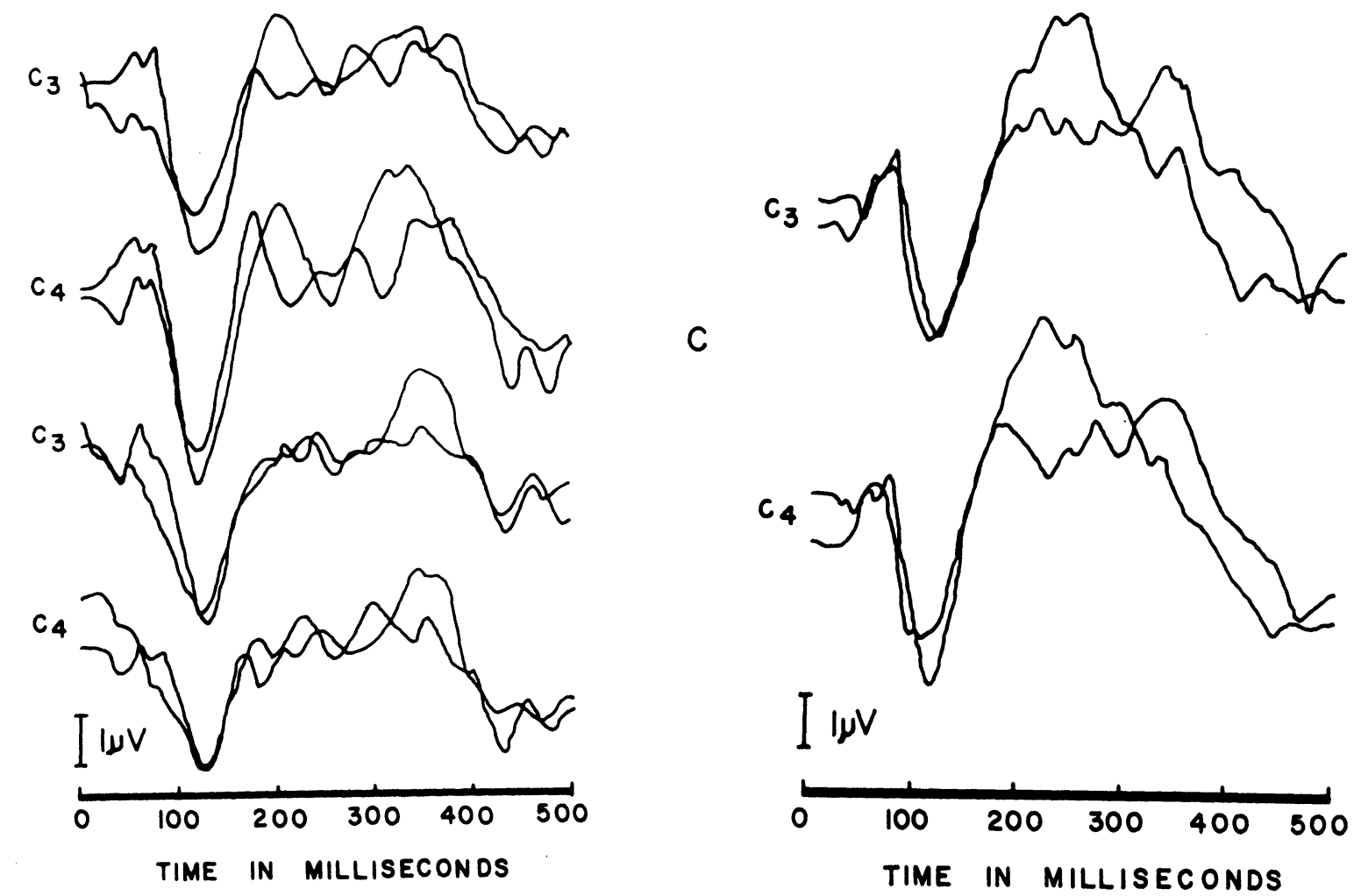

Figure 1. AEPs of one subject (L.C,) under Conditions A (left ear), B (right ear), and C (both ears). Traces are based on 150 representations. Negativity is downward. 